\title{
Impact of Gaps in Merit-Based Incentive Payment System Measures on Marginalized Populations
}

Kyle Eggleton, $M B C b B, M M e d S c i$, $M P H^{1}$

Winston Liaw, MD, MPH ${ }^{2}$

Andrew Bazemore, MD, MPH ${ }^{2}$

'The University of Auckland, Auckland, New Zealand

${ }^{2}$ The Robert Graham Center,

Washington, DC

\begin{abstract}
As the United States enters a new era of value-based payment heavy in emphasis on primary care measurement, careful examination of selected measures and their potential impact on outcomes and vulnerable populations is essential. Applying a theoretical model of health care quality as a coding matrix, we used a directed content analysis approach to categorize individual Merit Based Incentive Payment System (MIPS) measures. We found that most MIPS measures related to aspects of clinical effectiveness, whereas few, if any, related to aspects of access, patient experience, or interpersonal care. These gaps suggest that MIPS may fail to measure the broader aspects of health care quality and even risk worsening existing disparities.
\end{abstract}

Ann Fam Med 2017;15:255-257. https://doi.org/10.1370/afm.2075.

\section{INTRODUCTION}

$\mathrm{P}$ rimary care plays an important role in improving health outcomes and reducing health inequities for marginalized populations. ${ }^{.}$One mechanism of incentivizing primary care professionals to improve health outcomes is through pay-for-performance programs, where payers pay for value rather than merely services. Although pay-for-performance programs may lead to overall improvements, there is some evidence to suggest that they may inadvertently exacerbate health disparities for marginalized populations. ${ }^{2}$ This outcome is hypothesized to occur by encouraging physicians to focus on easily reportable measures rather than measures that make a difference for marginalized populations, to avoid patients that may harm quality measures, and to decrease the income and resources of physicians working in marginalized communities. ${ }^{2}$ The potential for the Medicare Access and CHIP Reauthorization Act (MACRA) Merit-Based Incentive Payment System (MIPS), the full implementation of which begins in 2017, to exacerbate health disparities was one of the concerns raised by the American Academy of Family Physicians in a letter to the Centers of Medicare and Medicaid Services (CMS). ${ }^{3}$ This general concern has led us to develop a taxonomy of measures used in MIPS to assess what gaps exist if a more specific focus on health disparities is to occur. Our hypothesis, that gaps may exist in MIPS, is informed by Starfield's argument ${ }^{1}$ that the measurement of quality in primary care requires person-focused assessments, measurements of the mode of delivery of health, and a focus on equity.

\section{METHODS}

The overarching method used in this study is a content analysis of proposed MIPS measures, published by CMS as of May 9, 2016. ${ }^{4}$ Our theoretical definition of quality of health care was developed by Campbell et $\mathrm{al}_{1}{ }^{5}$ which provided the basis for a coding matrix. A coding matrix allows researchers to integrate well-known concepts of quality. For example, quality is commonly understood to involve aspects of access, effectiveness, and equity. Within the framework described by Campbell et al, each dimension 
of health care (structure, process, and outcome) has different domains that relate to dimensions of quality (access and effectiveness). We defined each preliminary code in the coding matrix. The first level of codes corresponded to health care quality dimensions, and the second level of codes related to domains of health care.

Each MIPS measure was reviewed by 2 authors (K.E. and W.L.) to determine whether it was applicable to primary care. All data specific to primary care were then individually coded by the first author, in NVivo for Mac 10.2.2 (QSR International), using the coding matrix previously described. We allowed for individual measures to have multiple codes, if believed appropriate. The coded data set was then reviewed and recoded by the second author. Where differences of opinion existed in coding between the 2 reviewing authors, a consensus process was used to determine the final coding.

\section{RESULTS}

A total of 143 of 270 measures applied to primary care Most of the domains that reflected quality of primary care were not represented in the MIPs measures. Five of 12 domains had no applicable measures, and only $10 \%$ of the measures fell into another 5 domains of primary care (Table 1$)$.

\section{DISCUSSION}

The development of a taxonomy of MIPS has identified a number of important gaps in various domains of quality. In particular, we have identified a paucity of measures of access and patient experience. This deficiency may inadvertently exacerbate health inequalities for marginalized populations.

Marginalized populations face numerous barriers in accessing health care. These access issues include physical and geographical barriers, affordability barriers, and a lack of responsiveness from physicians. Mechanisms to mitigate against and address barriers in accessing primary care are likely to indicate a responsive primary care physician. The absence of any meaningful measures specific to addressing access barriers for individual patients in MIPS may contribute to a lack of incentives to address these barriers. ${ }^{7}$

MIPS also lacks the relational measures of user experience or physician interpersonal skills, which Starfield ${ }^{1}$ emphasizes as an essential aspect of quality. The importance of relationship to healing, that positive patient-physician interactions can improve health outcomes, may be particularly important to measure among vulnerable populations. ${ }^{8}$ In these groups, there is evidence that the quality of interpersonal health communication is poorer. ${ }^{9}$ Incorporating more personfocused measures rather than the current emphasis on disease-focused measures of MIPS may enable family physicians to better address aspects of practice that contribute to health disparities.

Our study has a number of limitations. The most important limitation is the lack of blinded double coding. Although 2 researchers coded the data, the second researcher was not blinded to the first researcher's coding, potentially introducing bias. Another limitation is that our analysis is on the combined MIPS measures, not the implemented MIPS measures. Although the

Table 1. Comparison of Coding Outcomes for Domains of Merit-Based Incentive Payment System Measures

\begin{tabular}{|c|c|c|c|c|}
\hline $\begin{array}{l}\text { Dimension of } \\
\text { Health Care }\end{array}$ & $\begin{array}{l}\text { Dimension } \\
\text { of Quality }\end{array}$ & Domain & Definition & No. $(\%)$ \\
\hline Structure & Access & $\begin{array}{l}\text { Geographical and } \\
\text { physical access }\end{array}$ & Geographical or physical barriers faced in getting to health services & $0(0)$ \\
\hline Structure & Access & Availability & $\begin{array}{l}\text { The extent to which a health service provides facilities that meet } \\
\text { the health needs of people }\end{array}$ & $0(0)$ \\
\hline Structure & Access & Affordability & $\begin{array}{l}\text { Financial barriers imposed on a person by a health care system/ } \\
\text { facility }\end{array}$ & $0(0)$ \\
\hline Structure & Effectiveness & $\begin{array}{l}\text { Structural } \\
\text { effectiveness }\end{array}$ & $\begin{array}{l}\text { The organization of a health facility that enables care to be deliv- } \\
\text { ered as intended }\end{array}$ & $0(0)$ \\
\hline Process & Access & Affordability & Financial barriers imposed on a person during the receipt of care & $4(3)$ \\
\hline Process & Access & Availability & $\begin{array}{l}\text { The extent to which a health service provides services that meet the } \\
\text { health needs of people }\end{array}$ & $5(3)$ \\
\hline Process & Effectiveness & $\begin{array}{l}\text { Effectiveness of } \\
\text { clinical care }\end{array}$ & $\begin{array}{l}\text { The effective application of knowledge based care (evidence based } \\
\text { or legitimate care) }\end{array}$ & $122(78)$ \\
\hline Process & Effectiveness & $\begin{array}{l}\text { Effectiveness of } \\
\text { interpersonal care }\end{array}$ & $\begin{array}{l}\text { Appreciation of the patient's personal experience of illness or } \\
\text { health care }\end{array}$ & $4(3)$ \\
\hline Outcome & Access & Health status & The clinical consequences of barriers in accessing care & $0(0)$ \\
\hline Outcome & Access & User evaluation & Experiences of patients in accessing health care & $1(<1)$ \\
\hline Outcome & Effectiveness & User evaluation & Experiences of patients in receiving heath care & $1(<1)$ \\
\hline Outcome & Effectiveness & Health status & The clinical consequences of the care that was provided & $19(12)$ \\
\hline
\end{tabular}


combined measures may not focus on marginalized populations, the implementation of MIPS is flexible, and family physicians are free to choose a small selection of MIPS measures that are more pertinent to marginalized populations. The final limitation is that certain domains of quality, such as affordability, may be best measured at the level of an organization or health funder rather than at the level of an individual physician.

We would posit that for MIPS and similar pay-forperformance programs to have a positive effect on health outcomes for marginalized populations, there is a need for policy makers to apply a theoretical lens to the measures. Even though we have used a theoretical framework devised by Campbell et al, ${ }^{7}$ other frameworks also exist. ${ }^{10}$ Applying a theoretical framework would involve ensuring that the broad domains of quality, equity in particular, are encapsulated by the proposed performance measures. In doing so, it is possible to identify gaps and subsequently develop measures that incentivize addressing health disparities. In neglecting to do so, pay-for-performance measures may fail in their objective of delivering better quality health outcomes for all members of society regardless of wealth, color, or personal circumstances. Even in the year of its inception, it is not too early for policy makers to be looking ahead toward improvements in MACRA and MIPS.

To read or post commentaries in response to this article, see it online at http://www.AnnFamMed.org/content/15/3/255.

Key words: quality of health care; reimbursement, incentive; pay for performance

Submitted November 20, 2016; submitted, revised, January 21, 2017; accepted February 8, 2017.
Previous presentation: Poster presentation at the NAPCRG Annual Meeting; November 12-16, 2016; Colorado Springs, Colorado.

\section{References}

1. Starfield B. New paradigms for quality in primary care. $\mathrm{Br} J \mathrm{Gen}$ Pract. 2001;51(465):303-309.

2. Casalino LP, Elster A, Eisenberg A, Lewis E, Montgomery J, Ramos D. Will pay-for-performance and quality reporting affect health care disparities? Health Aff (Millwood). 2007;26(3):w405-w414.

3. American Academy of Family Physicians. Response to the request for information regarding implementation of the merit- based incentive payment system, promotion of alternative payment models, and incentive payments for participation in eligible alternative payment models. American Academy of Family Physicians. http:// www.aafp.org/dam/AAFP/documents/advocacy/payment/medicare/ LT-CMS-MACRA-RFI-110915.pdf. Published Nov 9, 2015.

4. Goodrich, K. CMS finalizes its quality measurement development plan. The CMS Blog - the official blog for the Centers for Medicare and Medicaid Services. https://blog.cms.gov/2016/05/02/cmsfinalizes-its-quality-measure-development-plan/. Published May 9, 2016.

5. Campbell SM, Roland MO, Buetow SA. Defining quality of care. Soc Sci Med. 2000;51(11):1611-1625.

6. Browne AJ, Varcoe CM, Wong ST, et al. Closing the health equity gap: evidence-based strategies for primary health care organizations. Int J Equity Health. 2012;11(1):59.

7. Rosenthal MB, Frank RG. What is the empirical basis for paying for quality in health care? Med Care Res Rev. 2006;63(2):135-157.

8. Griffin SJ, Kinmonth AL, Veltman MW, Gillard S, Grant J, Stewart M. Effect on health-related outcomes of interventions to alter the interaction between patients and practitioners: a systematic review of trials. Ann Fam Med. 2004;2(6):595-608.

9. Saha S, Beach MC, Cooper LA. Patient centeredness, cultural competence and healthcare quality. J Natl Med Assoc. 2008;100(11): 1275-1285.

10. Donabedian A. The seven pillars of quality. Arch Pathol Lab Med. 1990;114(11):1115-1118. 